\title{
Studying groundwater and surface water interactions using airborne remote sensing in Heihe River basin, northwest China
}

\author{
CHUANKUN LIU ${ }^{1,2}$, JIE LIU ${ }^{1,2}$, YUE HU ${ }^{1,2}$ \& CHUNMIAO ZHENG ${ }^{1,2,3}$ \\ 1 Institute of Water Sciences, Peking University, Beijing, 100871, China \\ 2 College of Engineering, Peking University, Beijing, 100871, China \\ liuchuankun@pku.edu.cn \\ 3 Department of Geological Sciences, The University of Alabama, Tuscaloosa, Alabama 35487, USA
}

\begin{abstract}
Managing surface water and groundwater as a unified system is important for water resource exploitation and aquatic ecosystem conservation. The unified approach to water management needs accurate characterization of surface water and groundwater interactions. Temperature is a natural tracer for identifying surface water and groundwater interactions, and the use of remote sensing techniques facilitates basin-scale temperature measurement. This study focuses on the Heihe River basin, the second largest inland river basin in the arid and semi-arid northwest of China where surface water and groundwater undergoes dynamic exchanges. The spatially continuous river-surface temperature of the midstream section of the Heihe River was obtained by using an airborne pushbroom hyperspectral thermal sensor system. By using the hot spot analysis toolkit in the ArcGIS software, abnormally cold water zones were identified as indicators of the spatial pattern of groundwater discharge to the river.
\end{abstract}

Key words Heihe River Basin; airborne thermal infrared remote sensing; groundwater discharge; hot spot analysis

\section{INTRODUCTION}

Though surface water and groundwater were often managed and studied separately in the past, many hydrologists have now realized that surface water and groundwater are parts of a single and interconnected resource system (Winter et al., 1999). Understanding the spatial and temporal patterns of the interactions between surface water and groundwater is the foundation for the scientific water management and the maintenance of aquatic ecosystems (Webb et al., 2008; Fleckenstein et al., 2010). For semi-arid and arid regions, the water exchange between surface water and groundwater is the critical process of the entire water cycle (Constantz et al., 2003a). Tracers are widely used by hydrologists to indicate the interaction pattern between surface water and groundwater (Banks et al., 1996; Torgersen et al., 2001; Constantz et al., 2003b; Huang et al., 2012). Utilizing geochemical tracers in surface water and groundwater interaction studies bears the disadvantages of uncertainties from the spatial heterogeneity and measurement equipment errors. Environmental risk due to use of artificial tracers should be assessed carefully to avoid potential negative environmental influences. Temperature, as a natural and environment-friendly tracer, is easy to measure and more accessible (Anderson, 2005). With the development of remote sensing technologies, it is feasible to measure spatially continuous temperature on regional scales, thus greatly expanding the application of temperature in hydrological studies (Schmugge et al., 2002; Liu et al., 2014).

This study presents a relatively new methodology for identifying the spatial pattern of groundwater discharges to rivers semi-quantitatively on regional scales. Previous studies mainly focused on locating the concentrated discharge of groundwater on a local scale (Davis, 2007), and it remains a major challenge to characterize surface water and groundwater interactions on a regional scale because more complicated factors may affect the temperature distribution patterns on large scales.

\section{STUDY AREA}

This study utilized the Zhangye basin (Fig. 1) as the study area, a sub-basin of the middle Heihe River basin (HRB). The HRB is the second largest inland river basin located in northwest China between longitudes of $97^{\circ} 05^{\prime}$ to $102^{\circ} 00^{\prime} \mathrm{E}$, and latitudes of $37^{\circ} 45^{\prime}$ to $42^{\circ} 40^{\prime} \mathrm{N}$. The rapid population expansion and economic development have led to water overdraft in the middle HRB, causing the degradation of the ecosystem in the downstream. Accurate characterization and 


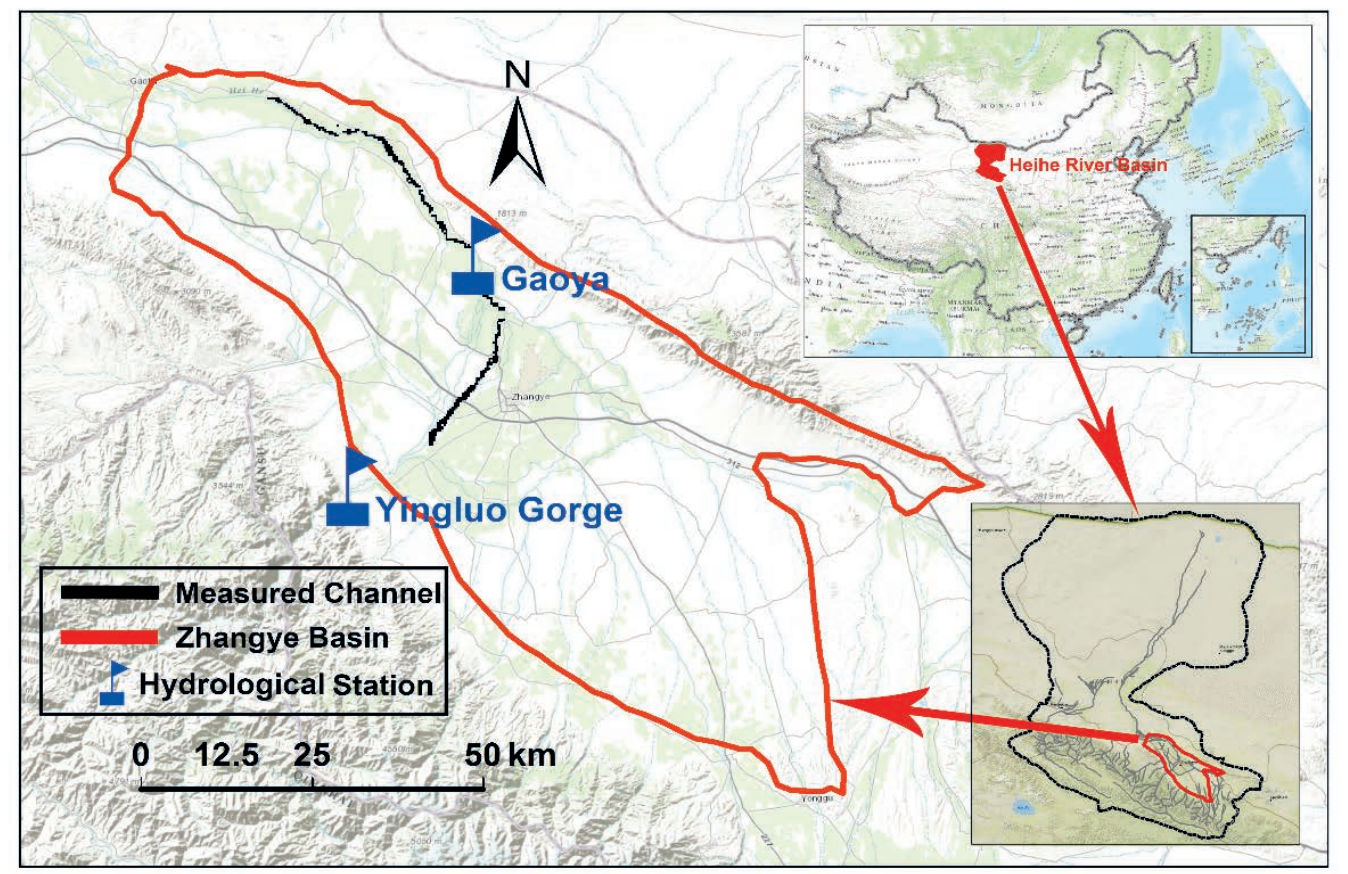

Fig. 1 Location of the Zhangye basin and the stream channels surveyed by airborne remote sensing.

understanding of the hydrological processes in the HRB is the foundation for sustainable water management and ecological protection.

The middle HRB has an area of $13624 \mathrm{~km}^{2}$. The average annual precipitation is about 100 to $200 \mathrm{~mm}$, with annual potential evaporation of more than $2000 \mathrm{~mm}$. Zhangye sub-basin is located in the eastern part of the middle HRB. The aquifers and aquitards in the fine soil plain of the subbasin are not horizontally continuous, and the water stored in different layers is hydraulically connected and exchanges frequently. The discharge to the Heihe, in the form of springs in Zhangye sub-basin, is $11.74 \times 10^{8} \mathrm{~m}^{3} /$ year. Considering that the total spring discharge in the HRB is $18.34 \times 10^{8} \mathrm{~m}^{3} /$ year and the average main stream runoff measured in the Yingluo Gorge is about $15.60 \times 10^{8} \mathrm{~m}^{3} /$ year (Cheng et al., 2009), it is obvious that groundwater discharge has a huge influence on the hydrological cycle in this area.

\section{AIRBORNE THERMAL INFRARED TEMPERATURE SENSING}

In this study, the river surface (top $0.1 \mathrm{~mm}$ ) temperature was detected by an airborne thermal infrared remote sensing system on 4 July 2012 covering $95 \mathrm{~km}$ of the main stream of the Heihe River in the Zhangye sub-basin (Fig. 1). The thermal sensor, the Thermal Airborne Spectrographic Imager (TASI), has 32 spectral channels and can detect radiation within the range $8-11.5 \mu \mathrm{m}$. The detection system was placed in a fixed wing aircraft and was capable of detecting noise equivalent temperature differences of $\pm 0.2^{\circ} \mathrm{C}$. The flight height of the aircraft was set to $833 \mathrm{~m}$ and the sensor's field of view is 40 degrees with 600 spatial imaging pixels in each scanning line, so the spatial resolution was $1.01 \mathrm{~m}$ which is adequate for the spatial analysis of river surface temperature (Handcock et al., 2006).

The meteorological data for the study site measured on 4 July 2012 were collected at Zhangye meteorological station. The daily average air temperature was $23.4^{\circ} \mathrm{C}\left(16.4-30.8^{\circ} \mathrm{C}\right)$, the relative humidity was $47 \%$, the surface wind speed was $3.7 \mathrm{~m} / \mathrm{s}$, and the average air pressure was 844.0 $\mathrm{hPa}(841.9-845.6 \mathrm{hPa})$. The flow rate measured at the Gaoya hydrological station was $27.5 \mathrm{~m}^{3} / \mathrm{s}$ on 4 July 2012, and the flow rate decreased along the downstream direction.

The accuracy of the remote sensing data was evaluated by linear analysis of the temperature data measured by land-based thermal infrared sensors versus the airborne thermal infrared sensed temperature data. The mission taken on 30 June 2012 with the same aircraft and remote sensing 
system covered 41 land-based sensors, and the mission taken on 10 July 2012 covered 42 landbased sensors. The analysis result shows that the ground truth data have a good match with the remote sensing data, with an adjusted $\mathrm{R}^{2}$ equal to 0.82 .

The land surface temperature data were used in the verification since no land based sensor was set in the river channel and the sensors covered by the airborne remote sensing mission were close enough to the river channel with a distance about $5 \mathrm{~km}$.

\section{DATA ANALYSIS}

For most natural rivers, the flow type tends to be turbulent flow which is irregular, unstable, and composed of many vortexes. The mixing effect of the turbulent flow brings the deep colder water to the river surface randomly, and thus it is reasonable to assume that the river surface temperature distribution is completely spatial random in the absence of inflows of distinctly different temperature. The higher the flow velocity, the more apparent the mixing effect is. The flow velocity in the middle part of the river channel is much faster than that closer to the river banks, and the river surface temperature demonstrates more obvious spatial randomness in the middle part than in the area near the river banks.

In this study, the groundwater is much colder than the surface water which means that the concentrated groundwater discharge would be identified as a cold plume in the measured temperature imagery of the river surface (Fig. 2 (a) and (b)). The river flow tends to be laminar flow when the flow velocity decreases, making the mixing effect of the turbulent flow less obvious and the vertical temperature stratification of the river remain. In the remote sensing imagery, the river surface temperature shows abnormally hot in the areas near the river banks and braided branches because of the relatively lower flow velocity there (Fig. 2(b)).
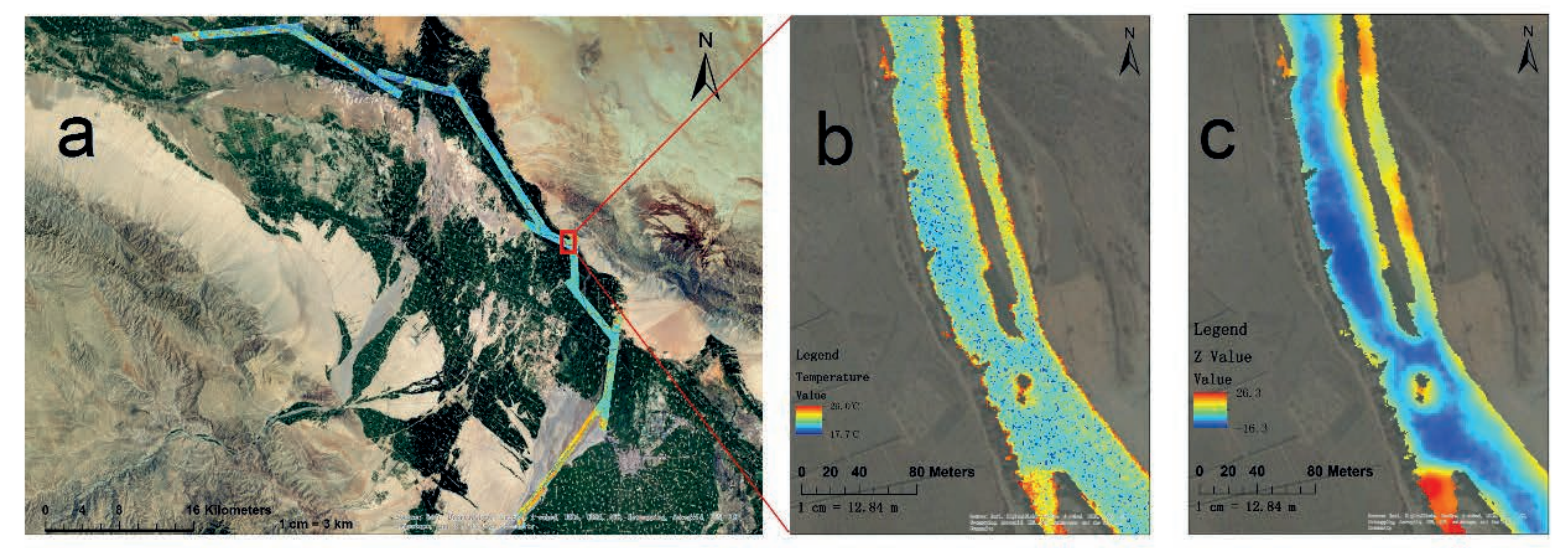

Fig. 2 (a) The surface temperature of the $90-\mathrm{km}$ long river channel measured by airborne temperature sensing; (b) a selected segment of the river surface imagery which indicates the spatial locations of the groundwater discharge by visual interpretation, and (c) the abnormal temperature clustering patterns which indicate the groundwater discharge zones.

In this study, the hot spot analysis (a toolkit integrated in the ArcGIS software ) is used to identify statistically significant hot spots and cold spots by the Getis-Ord Gi* statistic method, developed by Ord and Getis (1995). It is expected that the pixels nearby would have greater influence on a certain pixel than the farther ones, so the inverse distance was used for the conceptualization of the spatial relationships in the hot spot analysis. The output z-score indicates the temperature difference between a specified pixel and its surrounding pixels. In this study, the area with a $z$-score smaller than -2.58 (a p-value smaller than 0.01 , and a confidence level equalling to $99 \%$ ) was defined as a cold abnormal area, which indicates the spatial location of the concentrated groundwater discharge. It is important to classify a statistical channel sample with a relatively uniform width in the same scanned band to avoid the influence of temporal and spatial variations. 


\section{RESULTS AND DISCUSSION}

According to previously published papers, the spatial location of the groundwater discharge was usually directly identified by visual interpretation of the remote sensing imagery (Fig. 2(a) and (b)) (Banks et al., 1996; Torgersen et al., 2001). The visual interpretation is influenced by the interpreters' subjective factors and contains significant uncertainties. By using a hot spot analysis tool in ArcGIS, the spatial clustering pattern of the river surface temperature was obtained with the output field (z-score) identifying the spatial distribution pattern of the cold and hot abnormal areas under the assumptions mentioned above (Fig. 2(c)). The data clustering pattern is similar between Fig. 2(b) and (c), and the main advantage of Fig. 2(c) compared to Fig. 2(b) is that the cold plume in dark blue, which indicates groundwater discharge, can be identified more clearly. Under the assumption that the area with z-scores less than -2.58 is the area where concentrated groundwater discharge occurs, the spatial patterns of the groundwater discharge across the entire measured channels are identified. Taking the segment between the alluvial fan and the Beishan Mountains as an example, more groundwater discharge zones are found in the downstream direction (from south to north) indicating the decrease in the depth to the water table in the downstream direction and the effect of the less permeable aquifer sediments closer to the front of the Beishan Mountains (Fig. 3). The result shows that the hot spot analysis can be used to locate the groundwater discharge on both local (Davis, 2007) and regional scales. The spatial pattern could guide the following field work and act as an independent calibration dataset for coupled surface water and groundwater numerical models.
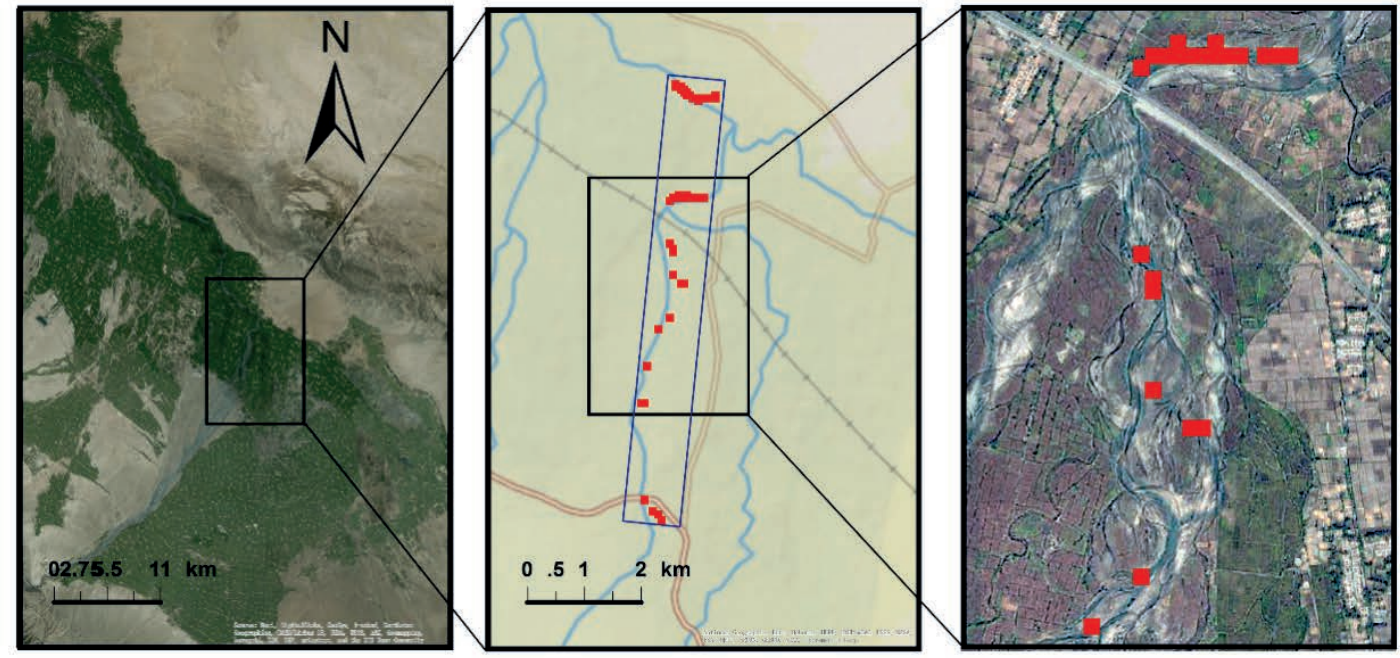

Fig. 3 The spatial pattern of the concentrated groundwater discharge along a segment of the surveyed river channel with a confidence level of $99 \%$, which is marked by red dots along the segment.

Diffusive groundwater discharge may be mixed by the river flow immediately and cannot be captured by airborne remote sensing, while concentrated groundwater discharge is regarded as dominating the groundwater discharge processes in the middle HRB, considering the spatial heterogeneity of the underlying aquifer. Defining the river flow as totally turbulent flow or laminar flow may be inaccurate, because the river flow shows more turbulent flow characteristics when the flow velocity becomes higher and more laminar flow characteristics with lower flow velocity. The assumption that the river surface temperature is completely spatially random would be more robust under the high flow period, during which the river flow acts more like turbulent flow.

\section{CONCLUSIONS}

Temperature is a natural and robust tracer for studying surface water and groundwater interactions. Most previous studies used temperature as independent calibration data for coupled surface water and groundwater models (Brookfield et al., 2009) or analysed the surface water and groundwater 
interaction pattern by direct visual interpretation (Banks et al., 1996; Torgersen et al., 2001). The construction of coupled models is time consuming and the visual interpretation is always influenced by subjective factors. The analysis based on airborne remote sensing temperature data can provide a general description of the surface water and groundwater interaction patterns quickly and accurately. In this study, the river surface temperature data from airborne thermal infrared remote sensing were analysed by using the hot spot analysis tool in ArcGIS, and the spatial locations of groundwater discharge were identified clearly. The critical assumptions made in this study would need more and further evaluation and analysis, but the method of data analysis has proven to be useful and robust. Further work should be done to quantify surface water and groundwater interactions using airborne remote sensing temperature data independently by taking full advantage of the spatially continuous temperature measurement over a regional scale.

Acknowledgements This study was supported by the National Natural Science Foundation of China (Grant Nos. 41271032 and 91225301). The authors are grateful to Qing Xiao, Jianguang Wen and Heshun Wang from the Institute of Remote Sensing and Digital Earth, Chinese Academy of Sciences for their assistance with the field work and data support.

\section{REFERENCES}

Anderson, M.P. (2005) Heat as a ground water tracer. Groundwater 43(6), 951-968.

Banks, W.S.L., Paylor, R.L., and Hughes, W.B. (1996) Using thermal infrared imagery to delineate groundwater discharge. Groundwater 34(3), 434-443.

Brookfield, A.E., et al. (2009) Thermal transport modelling in a fully integrated surface/subsurface framework. Hydrological Processes 23(15), 2150-2164.

Cheng, G., et al. (2009) Comprehensive management of hydrological-ecological-economic systems in the Heihe River Basin. Beijing: Science Press (in Chinese).

Constantz, J., Tyler, S.W., and Kwicklis, E. (2003a) Temperature-profile methods for estimating percolation rates in arid environments. Vadose Zone Journal 2(1), 12-24.

Constantz, J., Cox, M.H., and Su, G.W. (2003b) Comparison of heat and bromide as ground water tracers near streams. Groundwater 41(5), 647-656.

Davis, J.B. (2007) Aerial thermography surveys to detect groundwater discharge in the St. Johns River Water Management District, Northeast Florida. American Society of Photogrammetry and Remote Sensing, Annual Conference, Tampa, Florida, USA.

Fleckenstein, J.H., et al. (2010) Groundwater-surface water interactions: new methods and models to improve understanding of processes and dynamics. Advances in Water Resources 33(11), 1291-1295.

Handcock, R.N., et al. (2006) Accuracy and uncertainty of thermal-infrared remote sensing of stream temperatures at multiple spatial scales. Remote Sensing of Environment 100(4), 427-440.

Huang, L., et al. (2012) Application of distributed temperature sensing to study groundwater-surface water interactions in the Heihe River basin. Hydrogeology \& Engineering Geology 39(2), 1-6 (in Chinese).

Liu, C., et al. (2014) Advances in Using Temperature to Study Surface Water-Groundwater Interactions. Hydrogeology \& Engineering Geology 41(5), 5-10 (in Chinese).

Ord, J.K., and Getis, A. (1995) Local spatial autocorrelation statistics: distributional issues and an application. Geographical Analysis 27(4), 286-306.

Schmugge, T.J., et al. (2002) Remote sensing in hydrology. Advances in Water Resources 25(8), 1367-1385.

Torgersen, C.E., et al. (2001) Airborne thermal remote sensing for water temperature assessment in rivers and streams. Remote Sensing of Environment 76(3), 386-398.

Webb, B.W., et al. (2008) Recent advances in stream and river temperature research. Hydrological Processes 22(7), 902-918.

Winter, T.C. (1999) Ground water and surface water: a single resource. Darby: DIANE Publishing. 